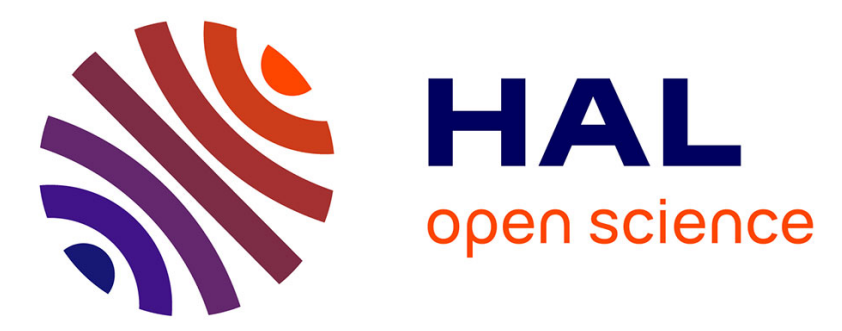

\title{
REDIFUEL: Robust and Efficient processes and technologies for Drop-In renewable FUELs for road transport
}

Benedikt Heuser, Andreas Vorholt, Gonzalo Prieto, Barbara Graziano, Sascha Schönfeld, Maarten Messagie, Giuseppe Cardellini, Sanna Tuomi, Nina Sittinger, Roy Hermanns, et al.

\section{To cite this version:}

Benedikt Heuser, Andreas Vorholt, Gonzalo Prieto, Barbara Graziano, Sascha Schönfeld, et al.. REDIFUEL: Robust and Efficient processes and technologies for Drop-In renewable FUELs for road transport. Transport Research Arena 2020, Apr 2020, Helinski, Finland. hal-02506871

\section{HAL Id: hal-02506871 \\ https://hal.science/hal-02506871}

Submitted on 12 Mar 2020

HAL is a multi-disciplinary open access archive for the deposit and dissemination of scientific research documents, whether they are published or not. The documents may come from teaching and research institutions in France or abroad, or from public or private research centers.
L'archive ouverte pluridisciplinaire HAL, est destinée au dépôt et à la diffusion de documents scientifiques de niveau recherche, publiés ou non, émanant des établissements d'enseignement et de recherche français ou étrangers, des laboratoires publics ou privés. 


\title{
Rethinking transport
}

\section{7-30 April 2020}

Proceedings of 8th Transport Research Arena TRA 2020, April 27-30, 2020, Helsinki, Finland

\section{REDIFUEL: Robust and Efficient processes and technologies for Drop-In renewable FUELs for road transport}

\author{
Benedikt Heuser $^{\mathrm{a} *}$, Andreas Vorholt ${ }^{\mathrm{b}}$, Gonzalo Prieto ${ }^{\mathrm{c}}$, Barbara Graziano ${ }^{\mathrm{a}}$, Sascha \\ Schönfeld $^{\mathrm{a}}$, Maarten Messagie ${ }^{\mathrm{d}}$, Giuseppe Cardellini ${ }^{\mathrm{d}}$, Sanna Tuomi ${ }^{\mathrm{e}}$, Nina Sittingerf \\ Roy Hermanns ${ }^{\mathrm{f}}$, Sangeetha Ramawamy ${ }^{\mathrm{f}}$, Chandra Kanth Kosuru ${ }^{\mathrm{g}}$, Hajo Hoffmann ${ }^{\mathrm{g}}$, \\ Linus Schulz ${ }^{\mathrm{h}}$, Jaykumar Yadavi, Maarten Weide ${ }^{\mathrm{j}}$, Thorsten Schnorbus ${ }^{\mathrm{a}}$
}

${ }^{a}$ FEV Europe GmbH, Neuenhofstr. 181, 52078 Aachen, Germany ${ }^{b}$ MPI Max-Planck-Institute for Chemical Energy Conversion CEC, Stiftstraße 34-36, 45470 Mülheim an der Ruhr, Germany ${ }^{c}$ Instituto de Tecnología Química (ITQ), Consejo Superior de Investigaciones Científicas-Universitàt Politècnica de València, Avd. Los Naranjos s/n, 46022, Valencia, Spain ${ }^{d}$ Vrije Universiteit Brussel, Boulevard de la Plaine 2, 1050 Bruxelles, Belgien ${ }^{e}$ VTT Technical Research Centre of Finland Ltd, Ruukinmestarintie 2, ESPOO, P.O. Box 1000, FI-02044 VTT, Finland ${ }^{f}$ OWI Oel-Waerme-Institut gGmbH, Kaiserstraße 100, Herzogenrath, Germany

${ }^{g}$ Tec4Fuels GmbH, Kaiserstraße 100, Herzogenrath, Germany ${ }^{h}$ INERATEC GmbH, Siemensallee 84, 76187 Karlsruhe, Germany ${ }^{i}$ Institute for Combustion Engines, RWTH Aachen University, 52074 Aachen, Germany ${ }^{j}$ Uniresearch, Elektronicaweg 16C, 2628 XG Delft, The Netherlands

\begin{abstract}
This paper introduces the work of the joint project "Robust and Efficient processes and technologies for Drop-In renewable FUELs for road transport" (REDIFUEL). The overall aim is to enable the utilization of various biomass feedstocks for an ultimate renewable EN590 diesel biofuel in a sustainable manner. REDIFUEL's ambition is to develop new technologies, solutions and processes to reach high conversion efficiencies for renewable fuel production. The proposed drop-in biofuel contains high-cetane liquid $\left(\mathrm{C}_{11}-\mathrm{C}_{21}\right)$ bio-hydrocarbons and $\mathrm{C}_{6}$ - $\mathrm{C}_{11}$ bioalcohols showing exceptional combustion and pollutant mitigation performance. Environmental and social aspects are also considered by carrying out a comprehensive Biomass-to-Wheel performance analysis.

First artificial fuel samples simulating the final product have been synthesized and analyzed with regard to fuel relevant properties, showing very promising results.
\end{abstract}

Keywords: Bioenergy; biofuels; transport; pollutant reduction; drop-in; EN590

\footnotetext{
* Corresponding author. Tel.: +49-241-5689-3947;

E-mail address: heuser@fev.com
} 


\section{Introduction}

The EU target for 2050 is to bring down the GHG emissions to only 5-20\% of the 1990 level that is crucial to lower the impact of global warming and climate change. The road transport sector, which contributed $95 \%$ of the EU's total transport-related GHG emissions in 2016, needs to achieve at least a $60 \%$ decrease in its GHG emissions. This represents a major challenge for the road transport sector, as it is nearly entirely based on internal combustion engines (ICEs) using fossil fuels.

Besides electrifying short-range transport of people and goods, it is clear that the ultimate solution is to entirely convert the remaining road transport to efficient powertrains running with $2^{\text {nd }}$ or $3^{\text {rd }}$ generation biofuels that comply with fuel economy targets as well as current and future emission standards. Furthermore, the ultimate solution must enable a fluent transition from dominantly fossil-based fuels to $2^{\text {nd }}$ or $3^{\text {rd }}$ generation biofuels in existing and future powertrains. Here, it is crucial to realize this goal with none or minor changes in infrastructures and with only little investments in the logistic chain.

This means that renewable fuels capable of drop-in mixing with fossil-based fuels and complying with current and future standards (i.e. EN228 for gasoline and EN590 for diesel) are needed. Furthermore, they must be cost competitive compared to existing fossil energy carriers and versatile regarding feedstock, production volume and time. This allows for a swift market introduction and a fluent transition from fossil-based energy carriers to biofuels.

Within the project "Robust and efficient processes and technologies for drop-in renewable fuels for road transport" (REDIFUEL), which is funded by Horizon 2020, 12 partners from all over Europe have joined forces. The overall aim is to enable the utilization of various biomass feedstocks for an ultimate renewable EN590 diesel biofuel in a sustainable manner. Due to its superior combustion behavior, REDIFUEL is not aiming for Fatty Acid Methyl Ester (FAME) biodiesel, but for a blend of long-chain alkanes and alcohols [Heuser et al., 2013, Klein et al., 2017 ]. The project structure is divided in several work packages with different research topics to achieve this ambitious goal.

The development of new processes and catalysts to produce such renewable fuels is carried out by Agencia Estatal Consejo Superior de Investigaciones Cientificas (CSIC), Teklologian tutkimuskeskus VTT Oy (VTT), and INERATEC GmbH with Max-Planck Gesellschaft zur Förderung der Wissenschaften eV (MPI) leading this work package. Neste leads the work package focusing on the evaluation of a biofuel-powered combustion system, including biofuel's compatibility with engine's components. Partners of this group are FEV Europe GmbH (FEV), RWTH Aachen University (RWTH), OWI Oel-Waerme-Institut GmbH (OWI), MOL Hungarian Oil and Gas Plc (MOL), and Tec4Fuels (T4F).

Jointly with MPI, Neste and INERATEC, VTT will do the scale-up and the corresponding process design and subsequently the pilot-plant testing.

\section{Development and scale-up of processes and catalysts for producing biofuels from renewable sources}

The process concept proposed in this project relies on the Fischer-Tropsch (FT) reaction for the production of synthetic hydrocarbons from bio-syngas. This polymerization-hydrogenation reaction takes place on the surface of suitable solid catalysts and is at the core of state-of-the-art Gas-to-Liquids (GtL) and Biomass-to-Liquids (BtL) processes. However, the innovative biofuel concept pursued in REDIFUEL requires a rather unconventional product distribution from this key conversion step. Next to the production of significant amounts of long-chain $\mathrm{C}_{11+}$ paraffins (alkanes) which, after hydrotreating upgrading, lead to the high-cetane backbone of the biofuel blend, the biogenic hydrocarbon FT products need to be unusually enriched in olefins (alkenes) with hydrocarbon chain lengths in the range of $\mathrm{C}_{5}-\mathrm{C}_{10}$ (see Figure 1). Given the unconventional FT product distribution sought after, the project entails significant $R \& D$ activities, encompassing from lab-scale developments to pilot-plant validation of novel FT-catalysts based on cobalt nanoparticles as the major active component. 

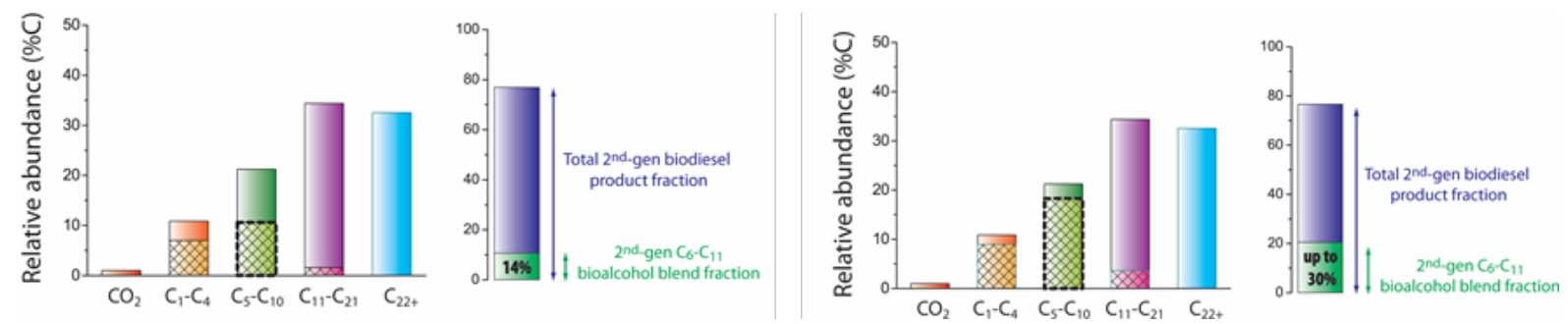

Figure 1. Schematic representation of the lumped product distribution with cobalt-based Fischer-Tropsch catalysts recently published by project partners (ref. 1, left panel) and projected to be developed within the REDIFUEL project (right panel). The dashed fraction of the bars correspond to olefin (alkene) hydrocarbons, while the full fraction represents paraffins (alkane). The plot on the right of the product distribution, shows the corresponding theoretical composition of the REDIFUEL biofuel blend.

In addition to the standard features of cobalt-based FT catalysts, i.e. essentially null by-production of $\mathrm{CO}_{2}$ alongside comparatively high polymerization chain-growth probabilities - which result in high selectivity to heavy hydrocarbon cuts (middle distillates and waxes) -, these materials are being designed to lead to hydrocarbon products enriched in liquid $\left(\mathrm{C}_{5}+\right)$ olefins. This $\mathrm{C}_{5}-\mathrm{C}_{10}$ olefin fraction coming from the FT-synthesis is key to the success in designing such a new renewable fuel. By upgrading this fraction into a sequence of hydroformylation and hydrogenation reactions, the olefins are converted to the corresponding $\mathrm{C}_{6}-\mathrm{C}_{11}$ alcohols [Torres, G. M., et al. 20115]. In total up to $30 \%$ of the final blend will consist of this bio-based synthetic alcohol mixture. These alcohols play a major role in the aim to reduce combustion emissions, since oxygenates lower soot emissions substantially [Janssen, A. J. et al. 2011; García, A. et al. 2018]. As alcohols are valuable chemical components with a variety of applications, there are several industrial paths for their production. The hydroformylation with a subsequent hydrogenation is commonly used to produce alcohols with small to medium chain lengths. Although the conventional reaction incorporates two reaction steps, cobalt based catalysts are able to directly produce alcohols from olefins in a single reaction step (tandem catalysis) [Achonduh, G. et al. 2015]. The amount of alcohols produced in this tandem reaction highly depends on the reaction conditions. Cobalt is known to need high temperatures and pressures for an effective catalysis. To get alcohols selectively in one reaction step, high temperatures $\left(>150^{\circ} \mathrm{C}\right)$ and pressures between 5 and $10 \mathrm{MPa}$ are needed (Shell process). The pressure range is especially important to get alcohols selectively in the case of cobalt. Pressures between 5 and $10 \mathrm{MPa}$ are necessary to get to the alcohol products but at the same time under these conditions the reaction is rather slow [Franke, R. et al., 2012]. This is why the catalytic activity is not high enough to produce them for fuel purposes although the Shell Process is the only known industrial process to produce alcohols directly from olefins.

One of the main challenges is the development of a process from an olefin mixture to alcohols with a highly active and highly selective catalytic system.

In general, two strategies can be followed on the catalytic side. A one-step approach, in which both reactions (hydroformylation and subsequent hydrogenation) take place in one reaction vessel (Figure 2, left). Alternatively, separate reactors and dedicated reaction conditions and catalysts can be applied for each reaction step [Torres, G. M. et al. 2015; Fuchs, S. et al. 2018].

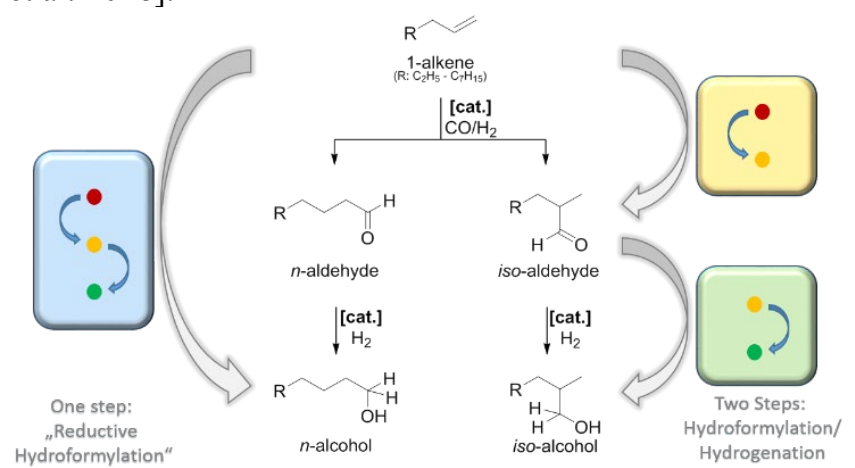

Figure 2. The two different approaches for the hydroformylation/hydrogenation reaction.

\subsection{One-Step Process}

The one-step process is superior in equipment cost because of streamlined process design [Behr, A. et al. 2014]. For this tandem reaction, new kinds of rhodium-based catalysts with cheap and stable ligands have been developed. 
The newly developed catalyst-system consists of a molecular rhodium amine complex that is able to catalyse the hydroformylation as well as the hydrogenation. The advantage of amine ligands are that they are inexpensive compared to commonly used phosphorous-based ligands and at the same time easy to remove from products by distillation. Furthermore, they are very stable against oxygen and other catalyst poisons, as one of their main applications is $\mathrm{CO}_{2}$ capture in severe conditions like exhaust gases or pressurized air [Puxty, G. et al. 2009]. The reaction conditions were optimised and all $\mathrm{C}_{5}-\mathrm{C}_{10}$ olefins from the FT-Process were converted into the corresponding alcohols with yields over $90 \%$.

\subsection{Two-Step Process}

A further important point for the industrial feasibility of the process concept is the recycling of the homogenous catalyst in its active form [Schrimpf, M. et al. 2019]. Very effective in this regard are water-based multiphasic systems combined with innovative reactor concepts for intensified mixing [Warmeling, H. et al. 2017].

A first process design is based on the scheme shown in Figure 3. The FT-products, olefins and paraffins are fed into the reactor while gas, consisting of hydrogen and carbon monoxide, is added. In a second step, a product phase is separated from the catalyst and is fed into a distillation column. The catalyst is recycled to the reactor. The subsequent hydrogenation in a second reactor converts the aldehydes to the desired alcohols.

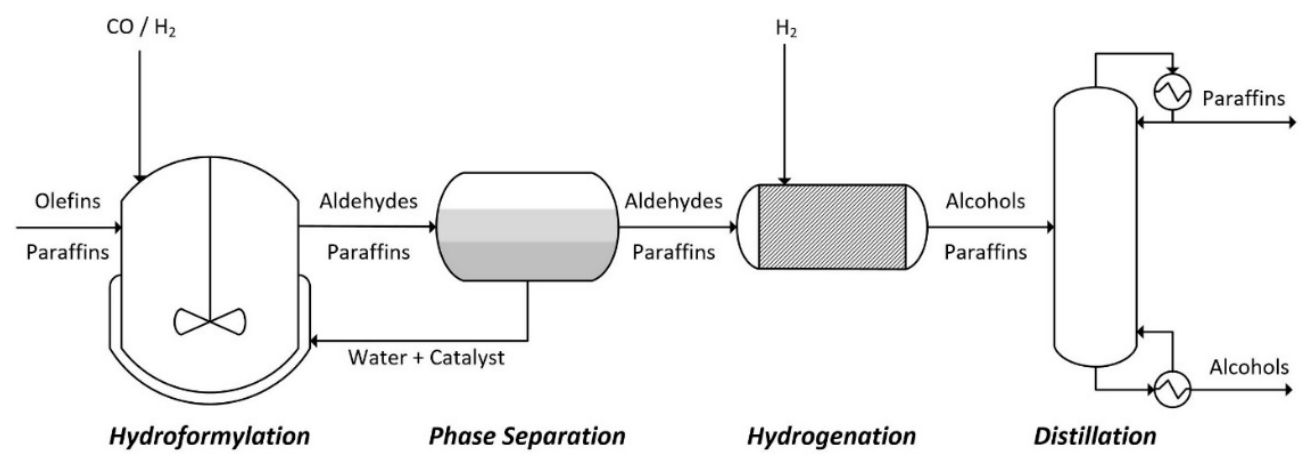

Figure 3. Process design based on the developed catalysts for a two-step process.

To meet flashpoint and density criteria of EN590, the paraffin share of the produced mixture needs to be removed. Based on a simulated distillation process, potential product compositions have been tested for their flashpoints. Due to only minor differences in thermophysical properties, the separation of longer chain paraffins (especially $\mathrm{C}_{10}$ in this case) from short chain alcohols $\left(\mathrm{C}_{6}\right.$ alcohol product $)$ is challenging. Flashpoint measurements showed that full removal of the $\mathrm{C}_{10}$ paraffin is not necessary, resulting in an efficient distillation process.

\section{Scale-up, pilot plant and process design}

Going from lab-scale to pilot plant scale, bio-syngas production via steam gasification lies at the root of the proposed REDIFUEL scheme. Biomass conversion into bio-syngas involves pre-processing of feedstock (drying, chopping etc.), gasification in a dual fluidised-bed gasifier followed by dedicated gas clean up. The main advantage of the applied dual fluidised-bed gasification technology is the feedstock-flexibility that originates from the relatively low operation temperature and pressure, which makes the technology suitable also for high alkali biomass feeds, such as straw. Moreover, the gasification process does not require oxygen production, which reduces the investment cost of the gasification plant making it applicable also for smaller scale $(<150$ MW feedstock input).

The raw gas formed in gasification needs to be cleaned, including particulate filtration, catalytic reforming of tars and light hydrocarbons, removal of minor impurities, such as $\mathrm{H}_{2} \mathrm{~S}$ and ammonia, and partial removal of $\mathrm{CO}_{2}$ prior to synthesis to meet the stringent gas quality requirements. The resulting bio-syngas, comprising primarily of $\mathrm{H}_{2}$ and $\mathrm{CO}$, has a $\mathrm{H}_{2} / \mathrm{CO}$ molar ratio of close to 2 and is as such applicable for FT-synthesis.

The first key processing step after gasification is a compact once-through FT-process where bio-syngas is converted into a hydrocarbon mixture enriched in $\mathrm{C}_{5}-\mathrm{C}_{10} \alpha$-olefins. The utilized compact microstructured reactor technology is equipped with an innovative evaporation cooling system, resulting in isothermal conditions even with highly exothermic FT-reactions. This feature is essential in the context of REDIFUEL as the presence of hot 
spots in the reactor is expected to severely deplete the FT-products in olefins by enhancing secondary hydrogenation reactions. Following synthesis, the FT-syncrude product is fractionated via distillation. The $\mathrm{C}_{11}+$ hydrocarbon fraction is hydrotreated into a diesel-like fuel, and the $\mathrm{C}_{5}-\mathrm{C}_{10}$ fraction is delivered to the second key processing step, hydroformylation, where $\mathrm{C}_{5}-\mathrm{C}_{10} \alpha$-olefins are hydroformylated and hydrogenated with bio-syngas into $\mathrm{C}_{6}-\mathrm{C}_{11}$ bio-alcohols.

The know-how gained in catalyst and synthesis development and hydroformylation optimization will be transferred to pilot plant level. The thermo-chemical conversion route starting from biomass gasification and gas clean up through FT-synthesis up to hydroformylation of the $\mathrm{C}_{5}-\mathrm{C}_{10}$ olefin fraction will be validated in pilot scale to reach TRL 5. The pilot test campaigns that are scheduled to start in 2020 encompass biomass gasification and FT-synthesis, processing of the $\mathrm{C}_{5}-\mathrm{C}_{10}$ olefin fraction and fractioning. The pilot plant will produce the novel biofuel in the scale of 200-300 litres that will be used in the fuel formulation and engine-related research and development. The overall process design and techno-economic analysis will be performed based on the results received from pilot-scale operation.

\section{Biofuel-fuel system compatibility aspects and engine related evaluation}

The final REDIFUEL will consist of mainly linear $\mathrm{C}_{6}-\mathrm{C}_{11}$ alcohols and a middle distillate part that mainly consists of slightly branched $\mathrm{C}_{11}-\mathrm{C}_{23}$ paraffins. Fuel formulation work will consider the different requirements towards different fuel product grades within the EU.

The produced alcohol sample has a density of $829.48 \mathrm{~kg} / \mathrm{m}^{3}$ which fits well into the EN 590 standard. One property of alcohols, which is determining the maximum amount of alcohol possible in the final blend, is the low cetane number (CN, self-ignitability of fuels) of the produced alcohols. Due to the high share of linear alcohols compared to branched ones $(\sim 2.5: 1)$, the self-ignitability of the fuel is improved, as linear molecules usually show higher CNs (Ratcliff et al., 2017). Moreover, also the chain-length distribution matches well with the requirements from fuel combustion. The mixture consists of alcohols with $\mathrm{C}_{6}-21 \%(\mathrm{~m} / \mathrm{m}), \mathrm{C}_{7}-20 \%(\mathrm{~m} / \mathrm{m}), \mathrm{C}_{8}-18.5 \%(\mathrm{~m} / \mathrm{m}), \mathrm{C}_{9}-$ $16 \%(\mathrm{~m} / \mathrm{m}), \mathrm{C}_{10}-13.5 \%(\mathrm{~m} / \mathrm{m})$ and $\mathrm{C}_{8}-11 \%(\mathrm{~m} / \mathrm{m})$.

Due to the limited availability of real products at this initial stage of the project, surrogate fuels had to be identified for initial testing. Thus, a mixture of linear alcohols (n-alcohols) that fits the carbon number distribution of simulation results has been chosen as surrogate for the alcohol mixture coming from the hydroformylation process. The properties of the surrogate alcohol mixture (SAM) have been tested and compare very well to the properties of the initially produced alcohol sample, see Table 1.

Table 1. Comparison of the surrogate alcohol mixture and the product alcohol mixture

\begin{tabular}{lll}
\hline Characteristics & Surrogate alcohol mixture (SAM) & Alcohol mixture from the process \\
\hline Density $\left(\mathrm{kg} / \mathrm{m}^{3}\right)$ & 828.1 & 829.5 \\
Viscosity $\left(\mathrm{mm}^{2} / \mathrm{s}\right)$ & 5.66 & 5.62 \\
Cetane number & 34.1 & 33.8 \\
\hline
\end{tabular}

Nevertheless, deviations in ignition temperature, oxidation stability and presumably in flashpoint have to be taken into account while interpreting the results of the initial testing. Similarly, for the hydro-isomerized middle distillate part Gas-to-Liquid (GtL) has been chosen as a surrogate because it consists of paraffins with similar chain lengths $\left(\mathrm{C}_{9}-\mathrm{C}_{22}\right)$.

Initial process calculation indicate that the maximum alcohol content of the first REDIFUEL batch will be maximum $30 \%(\mathrm{v} / \mathrm{v})$, thus leading to a paraffinic content of $\sim 70 \%(\mathrm{v} / \mathrm{v})$. Due to the high shares of paraffins, the product's density, and thus the surrogate's density, is only $791.7 \mathrm{~kg} / \mathrm{m}^{3}$. This is lower compared to the given limits in EN590, being minimum $820 \mathrm{~kg} / \mathrm{m}^{3}$ in summer time and $800 \mathrm{~kg} / \mathrm{m}^{3}$ for artic grades density. In order to keep the product's density as high as possible, the first fuel analysis and performance evaluation was done with the surrogate assuming a high alcohol content of $30 \%(\mathrm{v} / \mathrm{v})\left(\mathrm{REDIFUEL} \mathrm{RF}_{\mathrm{A} 30 \mathrm{P} 70}\right)$. This also was blended to diesel from fossil feedstock, since it is most likely that renewable fuels will be introduced into the market by blending into existing fuels.

In order to keep the share of renewable fuel high, it was decided to also evaluate a fuel blends of $46.5 \%$ (v/v) of each EN590 base fuel and REDIFUEL, with additional 7\% (v/v) used cooking oil methyl esters (UCOME) that 
typically have a high density. The investigated surrogate fuel blends and first analyses are presented in Table 2.

Table 2. Investigated fuel blends and their characteristics

\begin{tabular}{|c|c|c|c|c|c|c|}
\hline $\begin{array}{l}\text { EN590/REDIFUEL (GtL } \\
70 \% \mathrm{v} / \mathrm{v}+\text { alcohol } 30 \% \mathrm{v} / \mathrm{v})\end{array}$ & $0 / 100$ & $20 / 80$ & $50 / 50$ & $60 / 40$ & $80 / 20$ & $\begin{array}{l}46.5 / 46.5+ \\
7 \% \mathrm{v} / \mathrm{v} \text { UCOME }\end{array}$ \\
\hline Density at $15^{\circ} \mathrm{C}(\mathrm{kg} / \mathrm{m} 3)$ & 791.7 & 798.9 & 815.2 & 820.3 & 829.8 & 820.0 \\
\hline Viscosity at $40{ }^{\circ} \mathrm{C}(\mathrm{mm} 2 / \mathrm{s})$ & 3.01 & 3,01 & 3.02 & 3.03 & 3.09 & 3.01 \\
\hline CuCORR $3 \mathrm{~h}$ at $50{ }^{\circ} \mathrm{C}$ & $1 \mathrm{a}$ & $1 \mathrm{a}$ & $1 \mathrm{a}$ & $1 \mathrm{a}$ & $1 \mathrm{a}$ & $1 \mathrm{a}$ \\
\hline Carbon residue (wt $\%$ ) & $<0.1$ & $<0.1$ & $<0.1$ & $<0.1$ & $<0.1$ & $<0.1$ \\
\hline Distillation (range $\left.{ }^{\circ} \mathrm{C}\right)$ & $164-342$ & $164-346$ & $168-353$ & $170-354$ & $170-357$ & $169-353$ \\
\hline
\end{tabular}

Based on these first studies there are not much differences between the fuels, even the blend containing 7\% (v/v) UCOME show not much difference to the others. Minor differences are seen only in density and distillation end point.

Next to density, also the ignitability might be an obstacle for the REDIFUEL, since alcohols typically have a rather low self-ignition tendency. The indicated $\mathrm{CN}$ (ICN) of the initial alcoholic product and the fuel surrogate was measured by means of an Advanced Fuel Ignition Delay Analyzer ${ }^{\mathrm{TM}}$ (AFIDA), see [Seidenspinner, P., et, al 2015 ]. Figure 4 (left panel) introduces the results of this preliminary screening. 1-Octanol - as reference molecule for the long-chain alcohols - was measured to assess where the ignition tendency of this mixture stands.
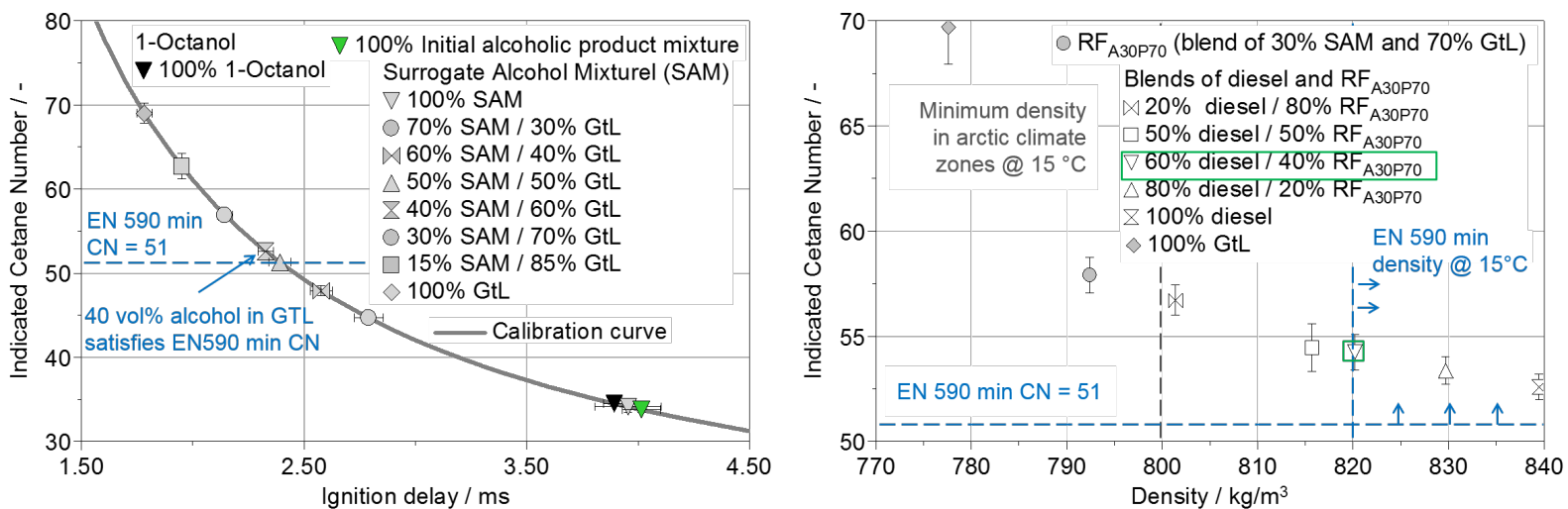

Figure 4: Indicated Cetane Number determination of Surrogate Alcoholic Fuel (SAF), real product mixture and blends of SAF and GtL (ref. 2, left panel), Indicated Cetane Number v/s density graph for different blends of REDIFUEL (ref. 2, right panel)

The SAM scores an ICN of 34 and matches very well to the real product that shows an ICN of 33.8. However, this is well below the minimum requirement of the EN590 that is $\mathrm{CN}=51$. Since the REDIFUEL blend consists not only of an alcohol fraction but also of n-paraffins, the ignition tendency can be increased increasing their share in the mixture. The GtL composition used for the surrogate is fully paraffinic without any additives [Shell GTL Fuel Knowledge Guide]. Figure 4 shows that a blend containing $40 \%$ (v/v) of SAM and $60 \%$ (v/v) GtL satisfies the minimum requirement of $\mathrm{CN}$ of EN590 norms. Hence, also $\mathrm{RF}_{\mathrm{A} 30 \mathrm{P} 70}$ scores a ICN of 56.9, and is well above EN590 ignition requirement.

The right panel of Figure 4 presents a trade-off between the density at $15^{\circ} \mathrm{C}$ and the $\mathrm{ICN}$ for $\mathrm{RF}_{\mathrm{A} 30 \mathrm{P} 70}$ blended with EN590 diesel in different proportions. The diesel used in this study is a standard diesel B0 without any biofuel content, having a density of $839 \mathrm{~kg} / \mathrm{m}^{3}$. Among the properties regulated in the EN590 the density is important because represents the volumetric energy content of a fuel [Ryan, Thomas, et al, 2008]. The density of the blends of diesel and $\mathrm{RF}_{\mathrm{A} 30 \mathrm{P} 70}$ increases with increasing share of diesel. However, opposite to the trend shown by the density, the ICN decreases with an increase of the diesel share, since it counteracts the high self-ignition tendency of the paraffins composing the GtL portion of $\mathrm{RF}_{\mathrm{A} 30 \mathrm{P} 70}$. The blend with $60 \%(\mathrm{v} / \mathrm{v})$ diesel and $40 \%(\mathrm{v} / \mathrm{v}) \mathrm{RF}_{\mathrm{A} 30 \mathrm{P} 70}$ satisfies both the minimum requirement for CN and density stated by the EN590 norm. Thus, this blend is chosen for future work on combustion system optimization using 3D-CFD simulations. 
To determine the drop-in-capability, the fuel is tested regarding EN 590 requirements as well as its material compatibility, storage stability and lubricant interactions. The material compatibility is assessed by a "Hardwarein-the-loop"-testing that involves all the components of a high-pressure fuel system such as high pressure pump, common rail, and injectors. This method can indicate the formation of both internal and external diesel injector deposits as well as the influence of the fuel on the high-pressure pump (lubricity) and compatibility of sealing materials in the fuel system.

In contrast to ignitability and density, the viscosity of $\mathrm{RF}_{\mathrm{A} 30 \mathrm{P} 70}$ is not critical at all and perfectly fits the EN590 regulation. It has a viscosity of roughly $3.05 \mathrm{~mm} / \mathrm{s}^{2}$ and its blends with diesel are comparable to that value. A property that has to be critically examined is the water content of the fuel. $\mathrm{RF}_{\mathrm{A} 30 \mathrm{P} 70}$ exceeds water content of the EN 590 standard about three times. This might be owed to its high content of hydrophilic alcohols. A consequence of the high water content of the fuels can be corrosion of metals in the fuel system. To prevent any effects in the engine a rescaling of the water separator might be necessary. A property that is relevant to security is the flashpoint. The flashpoint of $\mathrm{RF}_{\mathrm{A} 30 \mathrm{P} 70}$ was determined to be $61.5^{\circ} \mathrm{C}$ which is above the limit of $55^{\circ} \mathrm{C}$ even under consideration of the comparability of almost $4.4^{\circ} \mathrm{C}$ of the measuring method.

Additionally, an accelerated aging test method, BigOxy, has been developed and is being applied to evaluate the storage- stability of the developed fuels and blends. This method is a derivative of the PetroOxy method, which is used as a standard to measure a fuel's oxidation stability. While the PetroOxy is used to determine the oxidation stability of a few milliliters of fuel at a time, the BigOxy can be used for accelerated ageing of 100-500 ml of fuel. The ageing of large amounts of fuel in BigOxy enables a thorough analysis of the degraded fuel after testing and the testing of material samples within the fuel. The fuel is degraded in the test rig at high temperatures and pressures.

To assess the fuel's degradation a combined observation of different fuel ageing indicators like acid formation, water formation, oxygen consumption (autoxidation) and sediment formation is performed via a periodic analysis (aging time $0 \mathrm{~h}, 16 \mathrm{~h}, 32 \mathrm{~h}, 64 \mathrm{~h}$ ) of the fuel. Some of these ageing indicators such as the cold

properties will be discussed in the following section. The developments of the cold properties cloud point and cold filter plugging point of diesel fuel as well as $\mathrm{RF}_{\mathrm{A} 30 \mathrm{P} 70}$ and a blend of 50\% (v/v) diesel and 50\% (v/v) $\mathrm{RF}_{\mathrm{A} 30 \mathrm{P} 70}$ with respect to accelerated ageing are shown in Figure 6.

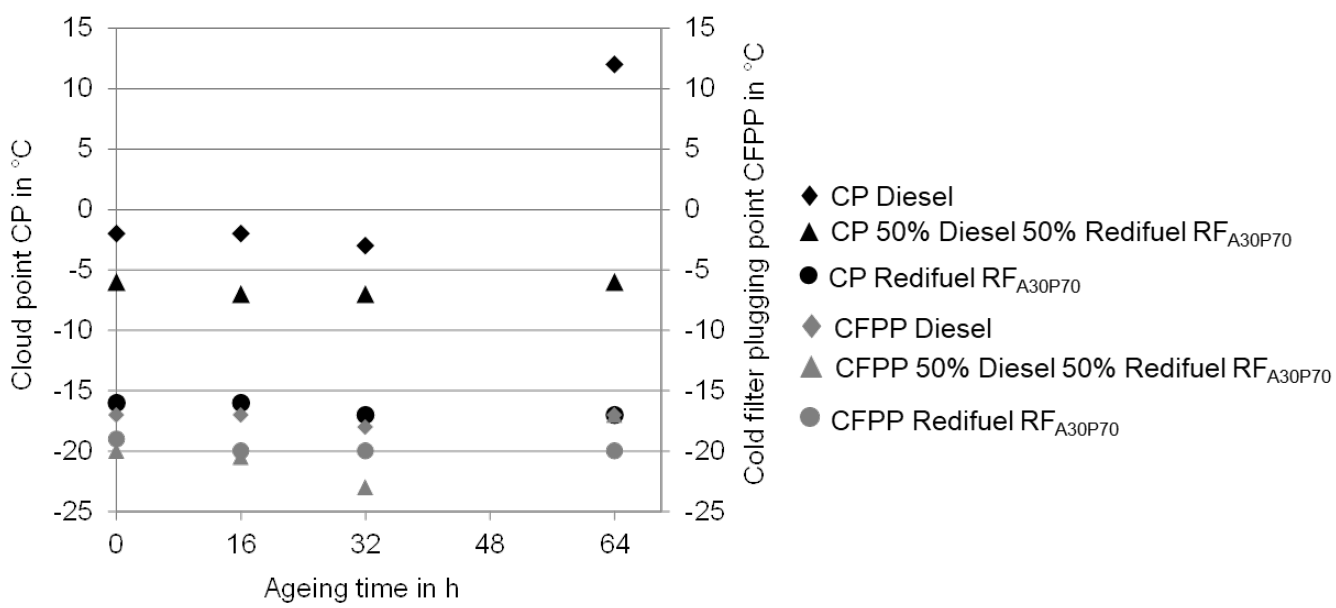

Figure 5. Cold Properties of diesel, $\mathrm{RF}_{\mathrm{A} 30 \mathrm{P} 70}$ and a blend of $50 \%(\mathrm{v} /)$ diesel and $50 \%(\mathrm{v} / \mathrm{v}) \mathrm{RF}_{\mathrm{A} 30 \mathrm{P} 70}$

The cold properties of $\mathrm{RF}_{\mathrm{A} 30 \mathrm{P} 70}$ are comparable with those of the conventional reference diesel. The deviation between the Cold Filter Plugging Point (CFPP) lie within the repeatability of the measuring method. The CFPPs of all fuels show little dependence on the ageing condition of the fuel. The Cloud Points $(\mathrm{CP})$ of $\mathrm{RF}_{\mathrm{A} 30 \mathrm{P} 70}$ are lower and thus favorable compared with the conventional diesel. The CPs of the blend of $50 \%(\mathrm{v} / \mathrm{v})$ diesel and $50 \%(\mathrm{v} / \mathrm{v})$ $\mathrm{RF}_{\mathrm{A} 30 \mathrm{P} 70}$ are located between those of the separate fuels. The CPs of $\mathrm{RF}_{\mathrm{A} 30 \mathrm{P} 70}$ as well as the blend show only little dependence on the ageing condition whereas the $\mathrm{CP}$ of aged diesel fuel increases from $-2{ }^{\circ} \mathrm{C}$ to $12{ }^{\circ} \mathrm{C}$ due to the degradation. This increase is beyond the reproducibility of the measuring method. $\mathrm{RF}_{\mathrm{A} 30 \mathrm{P} 70}$ and its blend with diesel satisfy the CFPP requirement of the standard EN 590 of class E for moderate climates without introduction of additives. 
The water content, which is already over three times the limit of the EN 590 standard for conventional diesel fuel of $200 \mathrm{ppm}$ for fresh $\mathrm{RF}_{\mathrm{A} 30 \mathrm{P} 70}$ still increases during ageing and reaches a value of $1770 \mathrm{ppm}$ at an ageing time of $64 \mathrm{~h}$. The blend's water content also increases with increasing ageing time and exceeds the EN 590 limit nearly 5 times $(961 \mathrm{ppm})$. This might be a consequence of the hydrophilicity of the alcohols contained in $\mathrm{RF}_{\mathrm{A} 30 \mathrm{P} 70}$. In contrary to that the water content of diesel fuel stays under the EN 590 limit.

Besides the fuel material interaction and the fuel storage capabilities, the fuel lubricant interaction is being assessed. On the one hand, possible impacts of the fuel on the lubricant are monitored; on the other hand, impacts of the lubricant on the fuel will be assessed. Parameters such as the density, viscosity, ignition delay and temperature as well as the lubrication itself and surface tension are investigated. Additionally, investigations with potentially stressed und contaminated lubricants out of the engine tests will be carried out.

To implement a renewable fuel as a drop-in-compatible fuel, it is important to verify the fuel compatibility with each and every component of the fuel system. Complete Common Rail System test benches namely "CoCoS" are hardware in the loop test benches used for testing the material compatibility of the fuel with individual components of the fuel system. This test bench serves as the premature testing of fuel compatibility without wasting higher quantities of fuel in engine test bench and also predict the phenomenon of fuel degradation and its effect on the components. This test bench requires as low as $30-60$ liters of fuel, which is a beneficial factor due to the lower availability of the fuel. This testing is highly cost effective and requires far less effort compared to an engine test bench for the preliminary testing of the fuel. (Hoffmann et al 2013)

Figure 6 (a) shows the general layout of the test bench, in which, all the fuel system components are connected in series. The fuel is pumped from the fuel tank (volume of fuel can vary) using an in-tank pump to the high-pressure pump. This high-pressure fuel (1200 bar - 2000 bar) is pumped to a common rail to which the injectors are connected. The fuel is then injected into a small reactor which is flushed initially with nitrogen to avoid any combustion. This fuel is then condensed or cooled down to around $40-60{ }^{\circ} \mathrm{C}$ using a heat exchanger and flows back to the fuel drum under gravity. The fuel pressure can vary depending on the requirement of the fuel system and the injector nozzle tip is heated to as high as $350{ }^{\circ} \mathrm{C}$ to simulate a temperature raise in the combustion chamber.
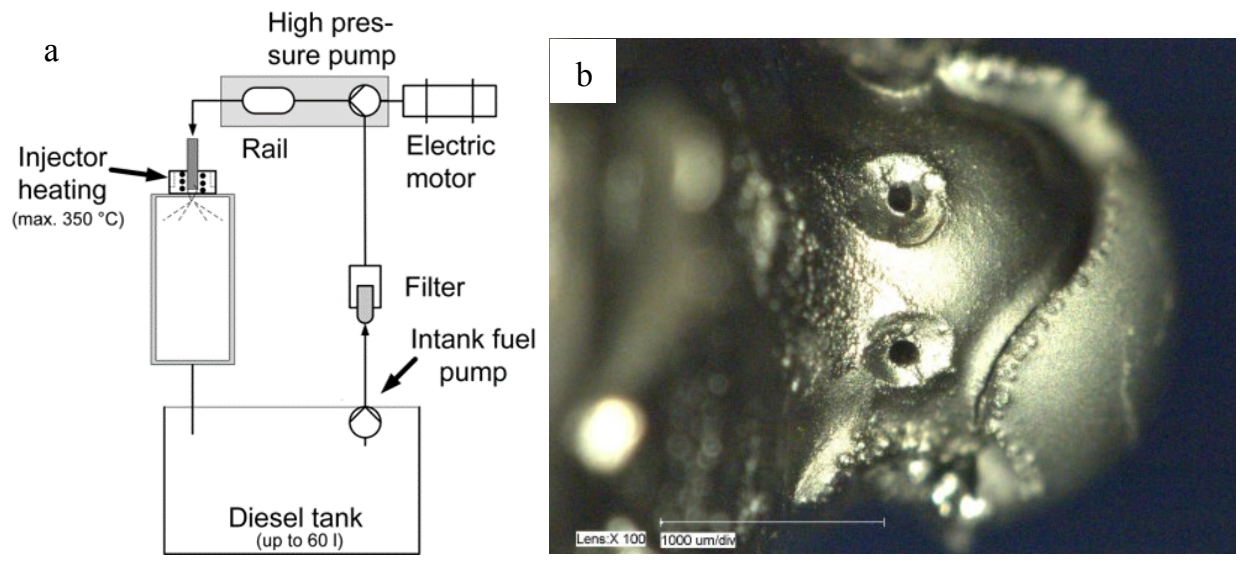

Figure 6: (a) General setup of one of the 4 test places at the "ENIAK" CoCoS test bench (Hoffmann, 2018); (b) External deposits after test run $(1,300$ bar, $10 \mathrm{~Hz}, 500 \mu \mathrm{s}, \mathrm{B} 10$ with performance additive) (Hoffmann et al, 2015)

This complete cycle is repeated for several hours $(100 \mathrm{~h}-500 \mathrm{~h}$ depending on requirement) in order to see the change in efficiency of the components such as pressure drop in fuel supply (pump wear), fuel flow reduction (blockage of components), or fuel leakage at different parts of the fuel system (failure in sealings). This method can also predict the deposit formation in injectors such as IDID (Internal diesel injector deposits) or EDID (External diesel injector deposits), see Figure 6 (b). The fuel is subjected to high thermal stress leading to degradation of fuel, which can induce corrosion on the fuel components and also lead to component failure. Also, the fuel properties before and after the testing can be analyzed to compare the fuel stability, increase in its acidic contents and metal contents due to component wear. 
For evaluation of the combustion performance and emission reduction potential, numerical 3D-CFD simulations have been performed. In this study, the mixture formation during the high pressure cycle of combustion under inert mixing condition is analysed using CONVERGE, a general purpose CFD tool that automates the mesh generation process and uses an algorithm for adaptive mesh refinement (AMR) [Richards, K. J, et al, 2017]. The cases simulated herein feature an average base grid of $1.4 \mathrm{~mm}$ and an additional mesh refinement yielding a local grid of minimum $0.35 \mathrm{~mm}$. To model with a good confidence level the mixture formation of the blend of $\mathrm{RF}_{\mathrm{A} 30 \mathrm{P} 70}$ with diesel, firstly the CFD model is calibrated using experimental data measured with a heavy-duty single cylinder engine (HD SCE) fuelled with diesel. Successively, the phisico-chemical properties of RF $\mathrm{A}_{\mathrm{A} 0 \mathrm{P} 70}$ are exchanged with the one of diesel fuel. The liquid properties of the renewable fuel are estimated using different models available in the literature [Viswanath, Dabir S., et al, 2007 and Yaws, Carl L, 2008] and considering 1-octanol as surrogate for the alcoholic share, a mixture of cyclooctane (45 vol\%), isocetane (51 vol\%) and n-decane (4 vol\%) as surrogate for GtL [Choudhury, H. A., et al, 2017], and DF-2 [Farrell, J. T., et al, 2007] for diesel fuel for the liquid phase. The gas-phase properties of the alcoholic components are modelled with 1-octanol, due to the very close ICN as shown in Figure 4. For GtL, a mixture of 20\% (v/v) n-heptane and n-dodecane $80 \%(\mathrm{v} / \mathrm{v})$ is chosen as surrogate since it resulted in the same ICN as GtL, and for diesel n-heptane is chosen as a surrogate [Farrell, J. T., et al, 2007]. To assess the quality of the mixture formation process the characteristic number "Air utilisation" is used. This non-dimensional number indicates the volumetric fraction of air inside the combustion chamber, sorted per air/equivalence ratios $(\lambda)$ ranges [Graziano, B., et al, 2014]. Figure 7 provides on the left-hand side a comparison of the air utilization for $\mathrm{RF}_{\mathrm{A} 30 \mathrm{P} 70}$ and diesel at a cruise point engine operation. It can be seen that $\mathrm{RF}_{\mathrm{A} 30 \mathrm{P} 70}$ has a larger share of lean mixture (i.e. Air utilization between $1<\lambda<2$ ), indicating a higher degree of air/fuel mixing and a high potential to oxidize soot during combustion. The right-hand side of Figure 7 shows cutsections of the piston bowl modelled in CONVERGE that corroborate the trends displayed by the air utilization curves. At the late combustion stages of 10 and 22 crank angle degrees $\left({ }^{\circ} \mathrm{CA}\right)$ a larger share of lean equivalence ratios can be seen and a smaller share of rich ones $(\lambda<1)$. This indicates that less likely not-oxidized soot is to be expected with $\mathrm{RF}_{\mathrm{A} 30 \mathrm{P} 70}$ in comparison with diesel. Thus, confirming the better mixture formation characteristics of this next generation biofuel.

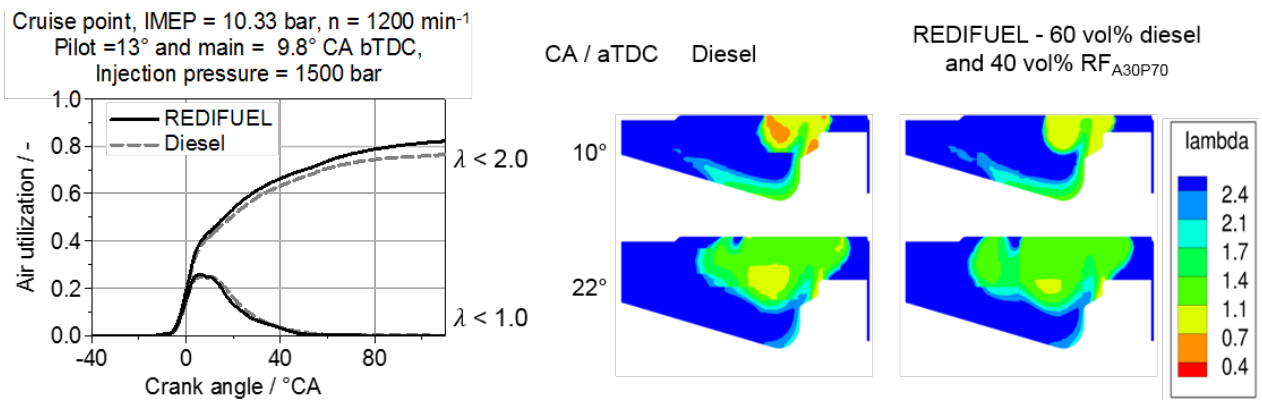

Figure 7: Comparison of Air utilization (ref. 3, left), and lambda plots for $\mathrm{RF}_{\mathrm{A} 30 \mathrm{P} 70}$ and diesel (ref. 3, right), at cruise power point

An initial fuel screening of this fuel has be conducted in an HD-SCE (Heavy Duty- Single Cylinder Engine) with a displacement of 2.13 liters and a compression ratio of 18.3. The fuel injection system used was a Bosch CRIN 4.2 with maximum injection pressure of up to 2700 bar. The HD-SCE is derived from the six-cylinder Daimler OM476 commercial vehicle engine. The first fuel investigations have been performed at and engine speed of $\mathrm{n}=1200 \mathrm{rpm}$ and at an indicated mean effective pressure of IMEP $=10 \mathrm{bar}$. This is the engine's cruise point, what is representing the engine's predominant operating region.

Figure 8 shows the engine test results for both EN590 diesel fuel and the fuel blend $60 \%(\mathrm{v} / \mathrm{v})$ diesel and $40 \%(\mathrm{v} / \mathrm{v})$ $\mathrm{RF}_{\mathrm{A} 30 \mathrm{P} 70}$. The baseline test were conducted by maintaining constant indicated mean effective pressure (IMEP) by adjusting injector energising duration, constant indicated specific NOx emission (ISNOx) by adjusting the exhaust gas recirculation (EGR) rate and constant centre of combustion $\left(\alpha_{\mathrm{Q} 50}\right)$. The other boundary conditions like boost temperature, fuel injection pressure $\left(\mathrm{p}_{\mathrm{inj}}\right)$, boost pressure $\left(\mathrm{p}_{\text {boost }}\right)$ and exhaust back pressure $\left(\mathrm{p}_{\text {exh }}\right)$ have been kept constant. When compared to the baseline diesel fuel, it is obvious that the blend of $60 \%(\mathrm{v} / \mathrm{v})$ diesel and $40 \%(\mathrm{v} / \mathrm{v})$ $\mathrm{RF}_{\mathrm{A} 30 \mathrm{P} 70}$ emits about $30 \%$ less soot emissions. This is attributed to the blend's different molecular structure. First, adding $\mathrm{RF}_{\mathrm{A} 30 \mathrm{P} 70}$ to diesel reduces the total aromatic content, since consists $\mathrm{RF}_{\mathrm{A} 30 \mathrm{P} 70}$ solely of $\mathrm{n}$-paraffins and $\mathrm{n}$ aclohols. Second, the fuel blend contains $\sim 3.5 \%(\mathrm{~m} / \mathrm{m})$ oxygen. Fuel bound oxygen is well known to substantially reduce engine out particulate matter [Mueller, C.J. et al. 2003]. Due to very similar mixture formation and almost identical ignition delay (see also Figure 9), neither the emission of hydrocarbons nor carbon monoxide are affected. However, due to an earlier end of combustion with $60 \%(\mathrm{v} / \mathrm{v})$ diesel and $40 \%(\mathrm{v} / \mathrm{v}) \mathrm{RF}_{\mathrm{A} 30 \mathrm{P} 70}$, the indicated thermal 
efficiency can be increase by $\sim 0.4 \%$ compared to EN590 diesel fuel.
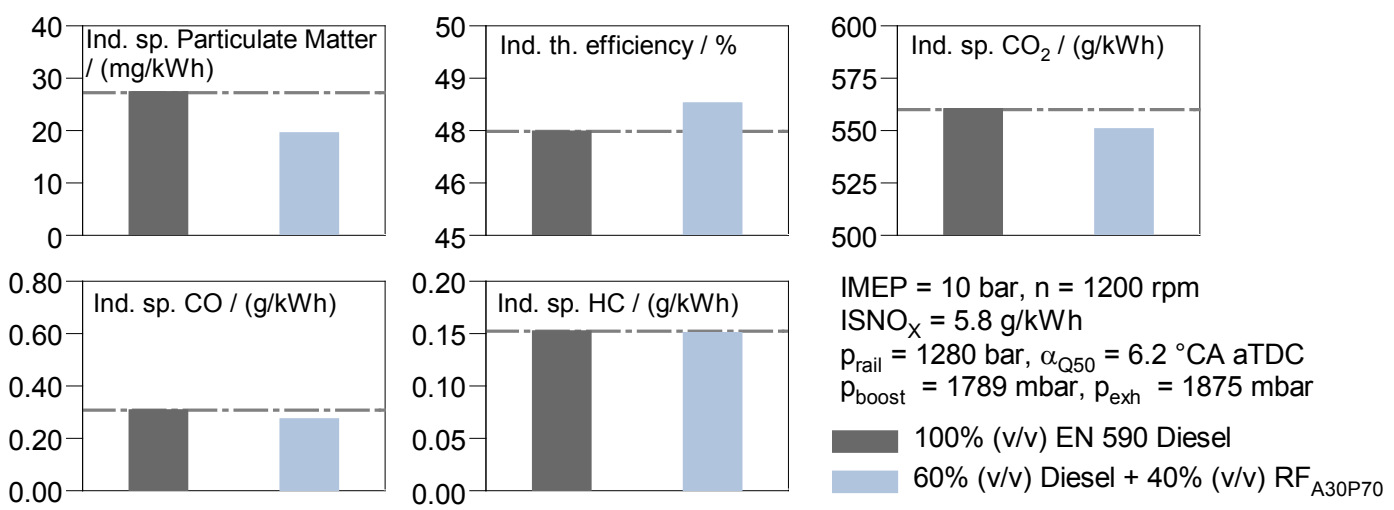

Figure 8. Engine test results of EN590 diesel and the blend of $60 \%(\mathrm{v} / \mathrm{v})$ diesel and $40 \%(\mathrm{v} / \mathrm{v}) \mathrm{RF}_{\mathrm{A} 30 \mathrm{P} 70}$ at $\mathrm{n}=1200 \mathrm{rpm}$ and IMEP $=10 \mathrm{bar}$

The in-cylinder pressure trace is given in Figure 9 (left); on the right side the heat release rate is shown. Obviously, the pressure trace, and thus the heat release rate, is equal for both fuels tested. This is mainly due to the very similar fuel characteristics being within EN590 regulation.
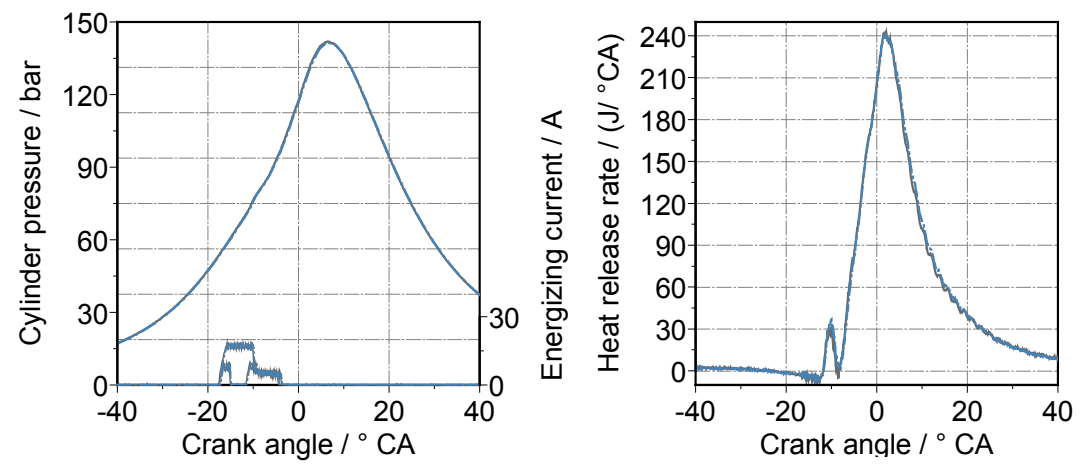

$100 \%$ EN590 Diesel

$60 \%(v / v)$ Diesel and 40\% (v/v) $R_{A 30 P 70}$

Figure 9. Cruise point baseline investigation

\section{Energetical conversion efficiency of a drop-in biofuel}

To assess the potential of the proposed drop-in biofuel, relative to conventional diesel and other biofuels, the overall conversion efficiency and environmental impact is investigated with a Life-cycle assessment (LCA) approach. This requires an inventory of all inputs and emissions related to feedstock production, transport processes, the thermochemical conversion, final fuel blending and the conversion process of the fuel into motion in the transport sector. State-of-the-art from the available literature shows that GHG saving potential of biomassto-liquid can be substantial (Figure 10), even though the process itself is not particularly energy-efficient (Figure 11). The focus of the LCA will also look at the broader picture of environmental impacts and investigate among other things land-use change, freshwater depletion, particulate matter and photochemical ozone formation.

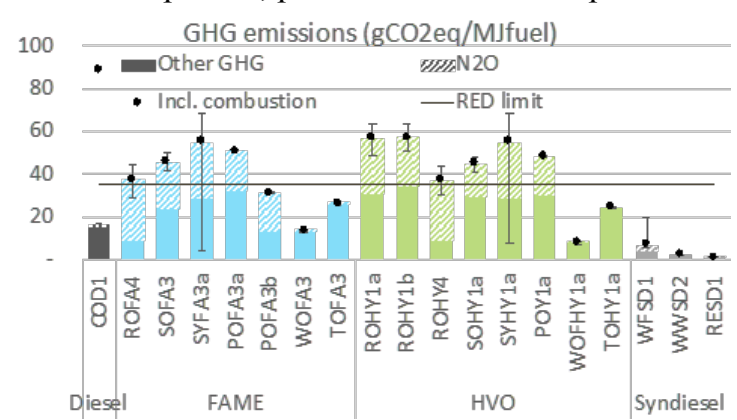

Figure 10: WtT GHG emissions of synthetic diesel compared to fossil diesel, FAME, and HVO expressed per MJ lower heating value of the obtained fuel. Combustion emissions for biofuels are assumed to equal zero. Combustion factor of fossil diesel if total combustion is supposed. Where available, error bars are added. Adapted from Edwards et al. (2013). 


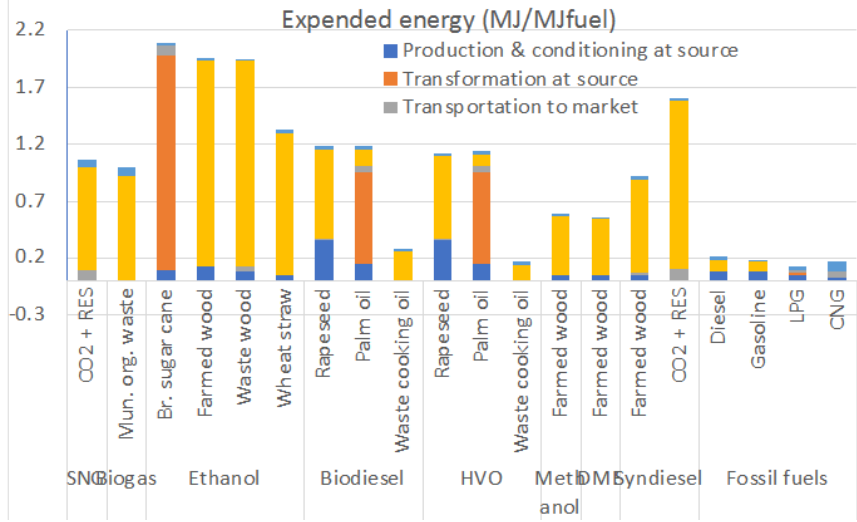

Figure 11: Energetic conversion efficiency of synthetic diesel compared to fossil diesel, fame, hvo and expressed per MJ lower heating value of the obtained fuel. Adapted from Edwards et al. (2013). For synthetic diesel production this study assumes an efficiency of $48.2 \%$, based on the work of Tijmensen et al. (2002).

\section{Conclusion and next steps}

REDIFUEL has developed pathways to synthesize drop-in capable renewable diesel fuels based on a biogenic feedstock. Catalysts for Fischer-Tropsch synthesis have been tailored that lead to an unconventional product pattern with high shares of $\mathrm{C}_{5}-\mathrm{C}_{10} \alpha$-olefins that subsequently will be processed to $\mathrm{C}_{6}-\mathrm{C}_{11}$ alcohols by hydroformylation. By adjusting catalyst and process parameters, a fuel can be produced that is fully compliant to EN590 regulation. Here, the most challenging parameters to fulfill are the minimum cetane number, the water content, and the fuel's density. Initial engine tests have revealed that the use of this alternative fuel - even when blended with fossil EN590 diesel - leads to a significant reduction in particulate matter emissions by up to $30 \%$. This consortium focuses on the use of biogenic products for synthesis gas production. However, also $\mathrm{CO}_{2}$ and $\mathrm{H}_{2}$ from renewable electricity, as well as municipal wasete, etc., could be used as feedstock.

Within the next two years, the consortium will prove the feasibility of this concept also in larger set-ups. Thus, the derived catalyst formulation will be employed also for the demonstration plant. This plant will produce sufficient amounts for the use in a series production demonstration vehicle. In the meantime, an optimal fuel formulation will be derived by all partners, taking into account mainly three boundary conditions:

- Compliance to EN590 regulation

- $\quad$ Target costs of $<1 € / 1_{\text {Dieselequivalent }}$

- The fuel's composition for reduced engine out emission

Moreover, the partners will optimize the combustion system for the use of the renewable fuel to further increase the combustion efficiency. Since the REDIFUEL product will contain a significant share of alcoholic components, also fuel interaction with the lubrication oil will be investigated.

The whole fuel development and combustion will be accompanied by a sophisticated Life-cycle analysis, to fully account for the environmental impact of the targeted fuels.

\section{Acknowledgements}

This project has received funding from the European Union's Horizon 2020 research and innovation programme under grant agreement No 817612.

\section{References}

Achonduh, G.; Yang, Q.; Alper, H., From alkenes to alcohols by cobalt-catalyzed hydroformylation-reduction. Tetrahedron 71, 1241-1246 (2015).

Behr, A.; Vorholt, A. J.; Ostrowski, K. A.; Seidensticker, T., Towards resource efficient chemistry: Tandem reactions with renewables, Green Chem. 16, 982-1006 (2014).

Choudhury, H. A.; Intikhab, S.; Kalakul, S.; Khan, M.; Tafreshi, R.; Gani, R.; Elbashir, N. O., Designing a surrogate fuel for gas-to-liquid derived diesel, Energy \& Fuels 31, 10 (2017): 11266-11279. 
Duyckaerts, N.; Bartsch, M.; Trotus, I.-T.; Pfänder, N.; Lorke, A.; Schüth, F.; Prieto, G., Intermediate Product Regulation in Tandem Solid Catalysts with Multimodal Porosity for High $C$ Yield Synthetic Fuel Production, Angew. Chem. Int. Ed., 56, 11480 (2017).

Edwards, R., Godwin, S., Krasenbrink, A., Huss, A., Maas, H., Hass, H., Lonza, L., Nelson, R., Reid, A., Rose, K.; Hamje, H., Well-to-wheels analysis of future automotive fuels and powertrains in the European context: tank-to-wheels report (TTW), version 4a, April 2014. Luxembourg: Publications Office (2014).

Farrell, J. T.; Cernansky, N. P.; Dryer, F. L.; Law, C. K.; Friend, D. G.; Hergart, C. A.; McDavid, R. M.; Patel, A. K.; Mueller, C. J.; Pitsch, H., Development of an experimental database and kinetic models for surrogate diesel fuels. No. 2007-01-0201. SAE Technical Paper (2007).

Franke, R.; Selent, D.; Börner, A., Applied hy droformylation, Chem. Rev. 112, 5675-5732 (2012).

Frey, G. D.; Roelen, O., 75 Years of Oxo Synthesis - The Success Story of a Discovery at the OXEA Site Ruhrchemie, J. Organoment. Chem., 754, 5-7 (2014).

Fuchs, S. et al., Synthesis of Industrial Primary Diamines via Intermediate Diols - Combining Hydroformylation, Hydrogenation and Amination, ChemCatChem 10, 4126-4133 (2018).

García, A.; Monsalve-Serrano, J.; Villalta, D.; Zubel, M.; Pischinger, S., Potential of 1-octanol and di-n-butyl ether (DNBE) to improve the performance and reduce the emissions of a direct injected compression ignition diesel engine, Energy Convers. Manag. 177, 563-571 (2018).

Graziano, B.; Perez, J. M.; Kremer, F.; Pischinger, S.; Reddemann, M. A.; Kneer, R.; Heufer, K. A.; Rohs, H., Virtual Fuel Approach: a new simulative methodology to analyse effects of fuel properties on mixture formation in compression ignition combustion (2014).

Heuser, B.; Kremer, F.; Julis, J.; Leitner, W., Optimization of Diesel Combustion and Emissions with Newly Derived Biogenic Alcohols, SAE Technical Paper Series (2013-01-2690) (2013).

Hoffmann, H.; Lucka, K., Hardware-in-the-loop testing: Complete Commonrail System (CoCoS) and component testing as rapid and costefficient tool in the introduction of alternative fuels in the automotive sector, 11. Tagung Einspritzung und Kraftstoffe, 359-372; Helmut Tschöke (Publisher), Ralf Marohn (Publisher), ISBN 978-3-658-23180-4, Springer-Vieweg, Germany (2018).

Hoffmann, H.; vom Schloß, H., Development of a Non-Engine Fuel Injector Deposit Test for Al-ternative Fuels (ENIAK-Project)", Bartz, W. J.: Fuels: Conventional and Future Energy for Au-tomobiles; 9th International Colloquium, January 15 - 17, 2013; TAE, Ostfildern, 613615, ISBN 98-3-943563-04-7 (2013).

Hoffmann, H., A Contribution to the Investigation of Internal Diesel Injector Deposits, Herzogenrath, Shaker Verlag GmbH, ISBN 978-38440-5953-3 (2018).

Hoffmann, H.; Sebastian, D.; Koch, W.; Lucka, K., Development of a Non-Engine Fuel Injector Deposit Fuel Test: Results, TAE, Ostfildern (2015).

Janssen, A. J. et al., Tailor-made fuels from biomass for homogeneous low-temperature diesel combustion, Energy and Fuels 25, 4734-4744 (2011).

Klein, D.; Pischinger, S., Laser-induced Incadescence Measurement of Tailor-Made Fuel in an Optical Single Cylinder Diesel Engine, SAE Int. J. Engines 10(3) (2017).

Koch, W.; Eiden, S.; Feldhoff, S.; Diarra, D., Development of a new stability test method for bio heating oils, DGMK Research-Report 763, ISBN 978-3-941721-82-1 (2017).

Puxty, G. et al., Carbon Dioxide Postcombustion Capture: A Novel Screening Study of the Carbon Dioxide Absorption Performance of 76 Amines, Environ. Sci. Technol. 43, 6427-6433 (2009)

Ratcliff, M. A., McCormick, R. L. \& Taylor, J. D. Compendium of Experimental Cetane Numbers Compendium of Experimental Cetane Numbers. (2017).

Richards, K. J.; Senecal, P. K.; Pomraning, E., CONVERGE 2.4 Manual, Convergent Science, Inc., Madison, WI (2017).

Ryan, T.; Maly, R. R., Fuel effects on engine combustion and emissions, Flow and combustion in reciprocating engines, 381-420, Springer, Berlin, Heidelberg (2008).

Schrimpf, M.; Esteban, J.; Rösler, T.; Vorholt, A. J.; Leitner, W., Intensified Reactors for Gas-Liquid-Liquid Multiphase Catalysis: from Chemistry to Engineering, Chem. Eng. J. 372, 917-939 (2019).

Sci, C.; Torres, G. M.; Frauenlob, R.; Börner, A.; Torres, G. M., Production of Alcohols via Hydroformylation, Catal. Sci. Technol., 5, 34-54 (2015).

Seidenspinner, P.; Härtl, M.; Wilharm, T.; Wachtmeister, G., Cetane Number determination by Advanced Fuel Ignition delay Analysis in a New Constant Volume Combustion Chamber, SAE Technical Paper No. 2015-01-0798 (2015).

Shell GTL Fuel Knowledge Guide, Version 2.0, Synthetic Technology for cleaner air, Shell, available online: https://www.shell.com/businesscustomers/commercial-fuels/shell-gtl-fuel/technicalinformation/_jcr_content/par/relatedtopics.stream/1496056917944/5bbe2047ad53280f54ce84ba3f824c68ef8be723/shell-gtl-fuelknowledge-guide-en.pdf [25-04-2019].

Tijmensen, M. J. A.; Faaij, A. P. C.; Hamelinck, C. N.; Van Hardeveld, M. R. M., Exploration of the Possibilities for Production of Fischer Tropsch Liquids and Power via Biomass Gasification, Biomass and Bioenergy 23, 129-52 (2002).

Torres, G. M.; Frauenlob, R.; Franke, R.; Börner, A., Production of alcohols via hydroformylation, Catal. Sci. Technol. 5, 34-54 (2015).

Viswanath, D. S.; Ghosh, T. K.; Prasad, D. H. L.; Dutt, N. V. K.; Rani, K. Y., Viscosity of liquids: theory, estimation, experiment, and data, Springer Science \& Business Media (2007).

Warmeling, H.; Janz, D.; Peters, M.; Vorholt, A. J., Acceleration of lean aqueous hydroformylation in an innovative jet loop reactor concept, Chem. Eng. J. 330, 585-595 (2017).

Mueller, C.J.; Pitz, W.J.; Pickett, L.M.; Martin, G.C., Siebers, D.L.; Westbrook, C.K., Effects of Oxygenates on Soot Processes in DI Diesel Engines, Experiments and Simulations (2003)

Winkle, J. L. Van; Lorenzo, S.; Morris, R.C.; Mason, R. F.; Valley, M., United States Patent Office (1969).

Yaws, C. L., Thermophysical properties of chemicals and hydrocarbons, William Andrew (2008). 